\title{
Determination of oxygen content in pulsed laser deposited InN thin films with analytical electron microscopy
}

\author{
Goran Drazic*, Evangelia Sarantopoulou**, Zoe Kollia**, Alciviadis-Constantinos Cefalas**, \\ Spomenka Kobe* \\ *Jozef Stefan Institute, Department for Nanostructured Materials, Jamova 39, \\ SI-1000 Ljubljana, Slovenia \\ **National Hellenic Research Foundation, 48 Vassileos Constantinou Avenue, \\ Athens 11635, Greece
}

Indium nitride is a promising material due to its potential applications in energy and optoelectronic devices, such as high efficiency solar cells, optical coatings, various types of sensors, high-speed transistors, etc [1-4].

Although the band structure of GaN and AlN are rather well known, the band gap value of $\mathrm{InN}$ is still an open issue as the reported values in the literature show large discrepancies $(1.89 \mathrm{eV} /$ $0.65 \mathrm{eV}$ ) [5]. The arguments of the band gap issue comprise the incorporation of oxygen in the crystal lattice, the Moss-Burstein effect and the presence of indium precipitates [6-8], although the actual role of these effects have not yet clarified. Recent investigations indicated that the oxygen contamination plays the most prominent role for the physical properties of InN, but it might be not the only one. Although the stability of InN crystals against oxidization was extensively investigated, little is known for the long term oxidation of InN films, because the stability of InN film in ambient conditions indicates large variations.

In the present work, we prepared InN thin films using elemental In as a target in $\mathrm{N}_{2}$ environment by pulsed laser deposition (PLD) with fluorine $157 \mathrm{~nm}$ laser on Si substrates. The aim of the work was study of the oxygen content in the InN films using analytical electron microscopy. Special emphasis was on the determination of the difference in oxygen content between the as-deposited films and those exposed to atmospheric oxygen.

Small fragments of InN film were transferred to lacey-carbon coated $\mathrm{Ni}$ grid and examined in Jeol 2010 FEG STEM microscope. It was observed that samples were very sensitive to the electron irradiation, decomposing to pure In, so very mild conditions were used during the study (small condenser aperture size, spot size 4, short exposure times, etc.).Converging of the beam during EDXS analysis was also avoided.

Films were consisted of well crystallized nanoparticles with 2 to $50 \mathrm{~nm}$ in size (Fig. 1a). In EDXS spectra beside indium and nitrogen (and carbon and nickel from lacey-carbon coated $\mathrm{Ni}$ grid) substantial amount of oxygen were found.

The estimated ratio (from EDXS spectra) of nitrogen to oxygen for the small $(5 \mathrm{~nm})$ and larger $(>15 \mathrm{~nm})$ crystals was found to be different. This difference may be ascribed to the different absorption of characteristic $\mathrm{O}_{\mathrm{K} \alpha}$ and $\mathrm{N}_{\mathrm{K} \alpha}$ X-rays. Close inspection of mass absorption coefficients showed that due to $\mathrm{M}_{\mathrm{IV}}$ and $\mathrm{M}_{\mathrm{V}}$ absorption edges of In the mass absorption coefficients (MACs) of $\mathrm{O}_{\mathrm{K} \alpha}$ and $\mathrm{N}_{\mathrm{K} \alpha}$ in In are much different $\left(19,000 \mathrm{~cm}^{2} / \mathrm{g}\right.$ in first case and $3,700 \mathrm{~cm}^{2} / \mathrm{g}$ in the second case). Also due to $\mathrm{K}$ absorption edge of nitrogen the MACs of $\mathrm{O}_{\mathrm{K} \alpha}$ line in nitrogen is 17,000 and $\mathrm{N}_{\mathrm{K} \alpha}$ line $1,500 \mathrm{~cm}^{2} / \mathrm{g}$. On the other hand despite very high difference in MACs the crystals were very small. We calculate that the attenuation of $\mathrm{O}_{\mathrm{K} \alpha}$ line in $10 \mathrm{~nm}$ thick crystal with composition $0.5 \mathrm{InN}$ $0.5 \mathrm{In}_{2} \mathrm{O}_{3}$ would be around $10 \%$ and attenuation of $\mathrm{N}_{\mathrm{K \alpha}}$ line around $2 \%$. Taking into account these considerations we concluded that the difference in nitrogen to oxygen concentration in major part 
could not be ascribed to absorption effects. Differences in spectra suggesting that oxidization could be crystal size dependent. We assumed that the formation of $\operatorname{In}_{2} \mathrm{O}_{3}$ during the ablation /growth phase was negligible and the oxidation of InN phase should be taken place later by atmospheric oxygen. In the attempt to determine the extent of oxidation of InN film the quantitative EDXS was found to be unsuitable method. Due to high absorption of low energy characteristic X-ray lines the determination of nitrogen and oxygen would be extremely uncertain. The degree of oxidation of InN films was instead estimated with selected area electron diffraction (SAED). All diffraction spots (forming rings) in experimental patterns were explained with hexagonal $\mathrm{InN}$ and cubic $\operatorname{In}_{2} \mathrm{O}_{3}$ as shown in Fig $1 b$.

On rotational average of experimental SAED patterns the intensity distribution of the diffracted electrons was deconvoluted using DiffTools scripts in Gatan's Digital Micrograph software [9]. In next step SAED intensity distributions for pure $\mathrm{InN}$ and $\mathrm{In}_{2} \mathrm{O}_{3}$ were calculated using EMS program code [10]. Using linear combination approach (sum of weighted parts of both simulated distributions) we tried to get best fit between the experimental and calculated intensity distributions. We found that in the case of samples that were kept 6 months in air there is approximately equivalent amount of both phases (best fit with experimental pattern was obtained in the case of $0.5 \mathrm{InN}-0.5 \mathrm{In} 203$ ). In the sample that was kept in isopropanole for a similar period of time we found the best fit in the case of $0.8 \mathrm{InN}-0.2 \mathrm{In}_{2} \mathrm{O}_{3}$. These results are also in agreement with the assumption that oxidation is taking place after the deposition.

There is also possibility that certain amount of oxygen is present as an amorphous $\operatorname{In}_{2} \mathrm{O}_{3}$ or even In$\mathrm{O}-\mathrm{N}$ phase which could be not detected using described method.

\section{References}

[1] D.W. Jenkins et al, Phys. Rev. B 39 (1989) 3317.

[2] S. Strite et al, J. Vac. Sci. \& Technol. B 10 (1992) 1237.

[3] H. Lu et al, J. Appl. Phys. 96 (2004) 3577.

[4] Y. M Meziani et al, Phys. Status Solidi a 202 (2005) 590.

[5] A. G. Bhuiyan et al, J. Appl. Phys. 94, (2003) 2779.

[6] D. Alexandrov, et al, J. Cryst. Growth 269 (2004) 77.

[7] J. Wu, et al, Phys. Rev. B 66 (2002) 201403.

[8] T.V. Shubina, et al, Phys. Rev. Lett. 92 (2004) 117407.

[9] D. R. G. Mitchell, Mic. Res. Techn. 71 (2008) 588.

[10] P.A. Stadelmann, Ultramicroscopy 21 (1987) 131.

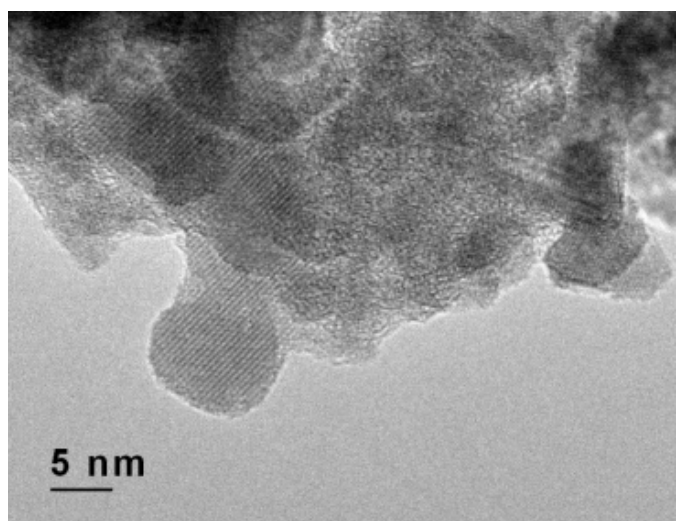

a.

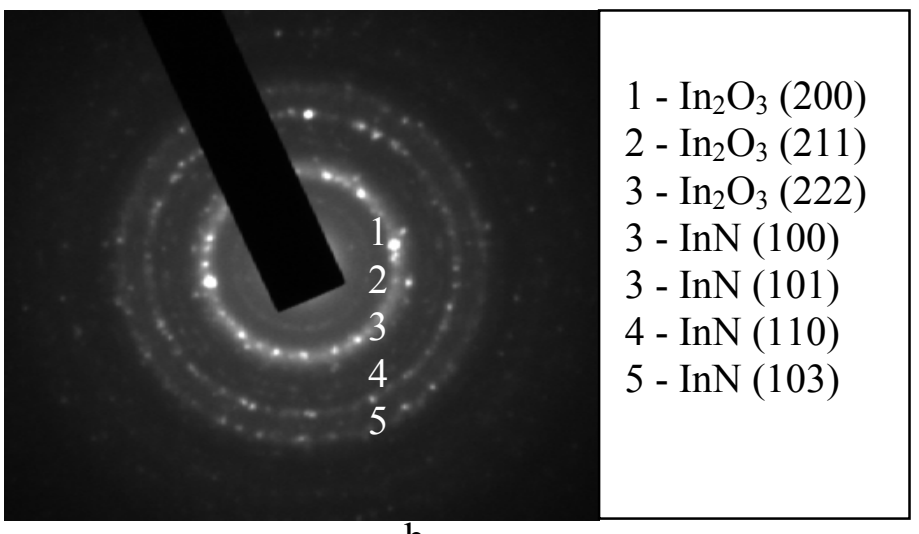

b.

FIG. 1a. - TEM micrograph of nanoparticles in InN thin film and 1b. - selected area electron diffraction pattern (SAED) of the sample stored for 6 months in air. 